\title{
FAKTOR-FAKTOR YANG BERHUBUNGAN DENGAN KEJADIAN PENYAKIT MALARIA DI WILAYAH KERJA PUSKESMAS ANGGUT ATAS KOTA BENGKULU
}

\author{
Suryani, Eprin Damayanti \\ Program Studi Kesehatan Masyarakat STIKES Tri Mandiri Sakti Bengkulu, Bengkulu, \\ Indonesia \\ Email :suryanilise@yahoo.co.id
}

\begin{abstract}
Abstrak
Malaria merupakan penyakit parasit yang penting di dunia, dan masih menjadi masalah kesehatan utama. Diperkirakan $41 \%$ penduduk dunia bermukim di daerah beresiko tinggi terinfeksi penyakit malaria terutama di daerah tropis dan subtropis. Penelitian ini bertujuan untuk mempelajari faktor-faktor apa saja yang berhubungan dengan kejadian penyakit malaria di Wilayah Kerja Puskesmas Anggut Atas Kota Bengkulu. Penelitian ini menggunakan Teknik Survey Analitik dengan rancangan cross sectional. Populasi dalam penelitian ini adalah seluruh jumlah suspek malaria yang berjumlah 122 responden. Sampel dalam penelitian ini berjumlah 40 responden, 20 malaria (+) dan 20 malaria (-). Pengumpulan data dalam penelitian ini menggunakan data primer dengan menyebarkan kuesioner. Dan data sekunder berupa data yang diperoleh dari hasil penelusuran studi dokumentasi pada catatan medis pasien yang dirawat di Puskesmas Anggut Atas Kota Bengkulu. Analisis data dilakukan dengan analisis univariat dan bivariat. Analisis bivariat bertujuan untuk mengetahui hubungan antara variabel bebas dengan variabel terikat dengan menggunakan uji statistik Chi-Square $\left(\chi^{2}\right)$. Hasil penelitian didapatkan;Terdapat 17 orang $(42,5 \%)$ dengan pengetahuan kurang. 21 orang (52,5\%) dengan sikap unfavourable di Wilayah Kerja Puskesmas Anggut Atas Kota Bengkulu. Terdapat 25 orang (62,5\%) tidak menggunakan kelambu. Terdapat 20 orang $(50,0 \%)$ mengalami kejadian malaria. Ada hubungan yang signifikan antara pengetahuan dengan kejadian penyaktit malaria, dengan kategori hubungan sedang. Ada hubungan yang signifikan antara sikap dengan kejadian penyaktit malaria, dengan kategori hubungan sedang. Ada hubungan yang signifikan antara pemakaian kelambu dengan kejadian penyaktit malaria, dengan kategori hubungan lemah.
\end{abstract}

Kata Kunci: Pengetahuan, Sikap, Pemakaian Kelambu, dan Malaria.

\section{PENDAHULUAN}

Malaria merupakan penyakit parasit yang penting di dunia, dan masih menjadi masalah kesehatan utama. Diperkirakan $41 \%$ penduduk dunia bermukim di daerah beresiko tinggi terinfeksi penyakit malaria terutama di daerah tropis dan subtropis. Angka kejadian malaria 350-500 juta kasus setiap tahunnya, dengan kematian lebih dari 1,1 juta, mayoritas kematian terjadi pada ibu hamil dan anak usia kurang dari 5 tahun. Malaria merupakan penyebab kematian no 4 di dunia setelah infeksi saluran pernapasan, HIV/AIDS dan Diare.

Malaria ditemukan lebih dari 100 negara terutama terbatas pada daerah tropis dari benua Afrika, Asia dan Amerika Latin. Penduduk yang berisiko terkena penyakit malaria berjumlah sekitar 2,3 milyar atau $14 \%$ dari penduduk dunia. Sejak tahun 2000 sampai 2012 rata-rata kematian akibat penyakit malaria pada 
sekelompok umur sebesar $45 \%$ dan $51 \%$ pada anak usia di bawah 5 tahun.

Malaria masih merupakan masalah kesehatan masyarakat di Indonesia karena angka morbiditas dan mortalitasnya yang masih tinggi terutama di daerah luar Jawa dan Bali. Malaria sudah dikenal sejak 3000 tahun yang lalu. Seorang ilmuwan Hippocarates (400-377 SM) sudah membedakan jenis-jenis malaria. Alphonse Laveran (1880) menemukan plasmodium sebagai penyebab malaria, dan Ross (1897) menemukan perantara malaria adalah nyamuk Anopheles. ${ }^{(3)}$ Etiologi penyakit malaria adalah parasit Plasmodium Vivax, $P$. Malariae, Falciparum dan $P$. Ovale, parasit golaongan sporozoa. Infeksi campuran jarang terjadi di daerah endemis.

Menurut data dari WHO, ada 214 juta kasus baru malaria di seluruh dunia pada tahun 2015 (kisaran 149-303000000). Daerah Afrika menyumbang sebagian besar kasus global malaria (88\%), diikuti oleh wilayah Asia Tenggara (10\%) dan Mediterania Timur Daerah (2\%). Pada 2015, diperkirakan ada 438000 kematian malaria (kisaran 236 000-635 000) di seluruh dunia. Sebagian besar kematian tersebut terjadi di Wilayah Afrika (90\%), diikuti oleh wilayah Asia Tenggara (7\%) dan Mediterania Timur Daerah (2\%). Antara tahun 2000 dan 2015, tingkat insiden malaria (kasus malaria baru) turun $37 \%$ secara global, dan sebesar $42 \%$ di Afrika.

Target Rencana Strategi Kementrian kesehatan untuk angka kesakitan malaria (API/Annual parasite inclidence) tahun 2013-2015 <1 per 1.000 penduduk berisiko. Dengan demikian cakupan API 2015 mencapai target Renstra.

Angka kesakitan malaria dalam bentuk API di Provinsi Bengkulu pada tahun 2015 sebesar 1,40 per 1000 penduduk. ${ }^{(7)}$ Berdasarkan data yang di ambil dari Dinas Kesehatan Kota Bengkulu jumlah klinis pada penyakit malaria pada tahun 2015 sebesar 19,49 dengan jumlah penduduk sebanyak 351.298 jiwa. ${ }^{(8)}$ Angka Kejadian malaria klinis pada tahun 2015 di Puskesmas Anggut Atas Kota Bengkulu sebanyak 49 kasus.

Munculnya penyakit malaria disebabkan oleh berbagai faktor yang menunjang vektor nyamuk Anhopeles bisa tetap survival karena penyusuaian terhadap lingkungan yang ada sehingga faktor yang pertama adalah lingkungan dalam hal ini : 1) lingkungan fisik termasuk suhu, kelembaban, hujan, tapografi, sinar matahari, angin, arus air, potensi perindukan nyamuk, iklim. 2) lingkungan kimiawi. 3) lingkungan biologi. 4) lingkungan sosial budaya termasuk kebiasaan berada diluar rumah sampai larut malam, menggunakan kelambu, memasang kawat kasa pada rumah dengan menggunakan abat nyamuk. Kemudian faktor yang kedua adalah prilaku dalam hal ini pengetahuan, sikap dan tindakan. Faktor yang ketiga adalah pelayanan kesehatan dan faktor yang keempat adalah hereditas.

Pengetahuan merupakan salah satu faktor yang mendorong terjadinya penyakit termasuk penyakit malaria. Pengetahuan tentang situasi malaria di suatu daerah akan sangat membantu program pemberantasan malaria dan berperan juga dalam melindungi masyarakat dari infeksi malaria agar paradigma sehat dapat diwujudkan.

Sikap merupakan reaksi atau respon yang masih tertutup dari seseorang terhadap stimulus atau objek. Sikap yang positif akan cenderung membawa masyarakat untuk bertindak dalam 
mencegah terjadinya penularan penyakit termasuk penyakit malaria. Sikap secara nyata menunjukkan konotasi adanya kesesuaian reaksi terhadap stimulus yang dalam kehidupan sehari-hari yang merupakan reaksi yang bersifat emosional terhadap stimulus social.

Sikap yang positif akan cenderung membawa masyarakat untuk bertindak dalam mencegah terjadinya penularan penyakit termasuk penyakit malaria.

Salah satu tindakan protektif yang bertujuan untuk mengurangi kontak manusia dengan nyamuk baik untuk orang per orang ataupun keluarga dalam satu rumah adalah dengan menggunakan kelambu tidur dengan atau tanpa insektisida pada saat tidur malam.

Berdasarkan penelitian awal pada 10 responden terdapat 6 yang menderita malaria dan 4 yang tidak menderita malaria. Dari 6 yang menderita malaria, 5 diantaranya mengaku kurang tahu akan pengetahuan akan penyakit malaria, dan 4 yang sikapnya masih kurang, dilihat dari jawaban responden yang belum menggunakan kawat kassa, memakai kelambu, dan menggunakan obat anti nyamuk pada saat malam hari. Dan 4 yang tidak menggunakan kelambu pada saat tidur.

Penelitian ini bertujuan untuk mengetahui gambaran pengetahuan, sikap, pemakaian kelambu, kejadian malaria serta mengetahui hubungan antara pengetahuan, sikap, pemakaian kelambu dengan kejadian malaria di wilayah kerja Puskesmas Anggut Aatas Kota Bengkulu.

\section{METODOLOGI}

Penelitian ini dilaksanakan di wilayah kerja Puskesmas Anggut Atas Kota Bengkulu. Penelitian ini dilakukan pada bulan September-Oktober 2017. Jenis penelitian yang digunakan adalah Survei Analitik., Desain penelitian yang digunakan mengunakan Cross Sectional yaitu melakukan observasi terhadap variabel dependen maupun independen yang kemudian di lalakukan suatu analisis variabel yang membandingkan faktor risiko (variabel independen) terhadap faktor efek (variabel dependen) pada saat atau priode yang sama.

Populasi penelitian ini adalah seluruh jumlah suspek malaria yang berkunjung dan tinggal di wilayah kerja Puskesmas Anggut Atas Kota Bengkulu tahun 2016 yang berjumlah berjumlah 122 responden. Sampel dalam penelitian ini berjumlah 40 responden, 20 malaria (+) dan 20 malaria (-). Teknik pengambilan sampel adalah Simple random sampling

Data yang dikumpulkan dalam penelitian ini meliputi data primer dan data sekunder. Data primer adalah data yang diperoleh dari survei dan wawancara langsung menggunakan kuesioner untuk mendapatkan data mengenai faktor resiko yang berhubungan dengan kejadian malaria dengan yaitu faktor pengetahuan, sikap, pemakaian kelambu, dengan cara menyebarkan kuesioner dengan mendatangi responden ke rumah-rumah.

Data sekunder adalah data yang dikumpulkan melalui laporan dan register pada buku Puskesmas Anggut Atas Kota Bengkulu sebagai penunjang suatu pelengkap. Data laporan bulanan Puskesmas Anggut Atas, data register yang datang berobat ke Puskesmas Anggut Atas Kota Bengkulu. Variabel bebas (Pengetahuan, sikap, pemakaian kelambu) dan variabel terikat (Kejadian Malaria) di wilayah kerja Puskesmas Anggut Atas Kota Bengkulu.

Teknik pengolahan data dilakukan 
dengan beberapa tahap yaitu editing, coding, data entry, cleaning. Teknik analisis data adalah analisis univariat dan bivariat. Data dianalisis dengan menggunakan uji statistik Chi-Square $\left(\chi^{2}\right)$. Untuk mengetahui keeratan hubungannya digunakan uji statistik Contingency Coefficient (C).

\section{HASIL PENELITIAN}

\section{Analisis Univariat}

Tabel 1. Distribusi Frekuensi Pengetahuan di Wilayah Kerja Puskesmas Anggut Atas Kota Bengkulu

\begin{tabular}{llcc}
\hline $\begin{array}{l}\text { N } \\
\text { o }\end{array}$ & Pengetahuan & Frekuensi & $\begin{array}{c}\text { Persentase } \\
(\%)\end{array}$ \\
\hline 1 & Kurang & 17 & 42,5 \\
2 & Cukup & 10 & 25,0 \\
3 & Baik & 13 & 32,5 \\
& Jumlah & 40 & 100 \\
\hline
\end{tabular}

Dari Tabel 1 menunjukkan bahwa dari 40 responden terdapat 17 responden $(42,5 \%)$ dengan pengetahuan kurang, dan 10 responden $(25,0 \%)$ dengan pengetahuan cukup dan 13 responden (32,5\%) dengan pengetahuan baik.

Tabel 2. Distribusi Frekuensi Sikap di Wilayah Kerja Puskesmas Anggut Atas Kota Bengkulu

\begin{tabular}{cccc}
\hline $\begin{array}{c}\mathrm{N} \\
\mathrm{o}\end{array}$ & Sikap & Frekuensi & $\begin{array}{c}\text { Persentase } \\
(\%)\end{array}$ \\
\hline 1 & Unfavourable & 21 & 52,5 \\
2 & Favourable & 19 & 47,5 \\
& Jumlah & 40 & 100 \\
\hline
\end{tabular}

Dari Tabel 2 menunjukkan bahwa 40 responden terdapat 21 responden $(52,5 \%)$ dengan sikap unfavourable dan 19 responden $(47,5 \%)$ dengan sikap favourable.

Tabel 3. Distribusi Frekuensi Pemakaian Kelambu di Wilayah Kerja Puskesmas Anggut Atas Kota Bengkulu

\begin{tabular}{|c|c|c|c|}
\hline $\begin{array}{l}\mathrm{N} \\
\mathrm{O}\end{array}$ & $\begin{array}{l}\text { Pemakaian } \\
\text { Kelambu }\end{array}$ & Frekuensi & $\begin{array}{c}\text { Persentase } \\
(\%)\end{array}$ \\
\hline 1 & $\begin{array}{l}\text { Tidak } \\
\text { Menggunakan }\end{array}$ & 25 & 62,5 \\
\hline 2 & $\begin{array}{l}\text { Menggunakan } \\
\text { Jumlah }\end{array}$ & $\begin{array}{l}17 \\
40\end{array}$ & $\begin{array}{l}37,5 \\
100\end{array}$ \\
\hline
\end{tabular}

Dari Tabel 3 menunjukkan bahwa dari 40 responden terdapat 25 responden $(62,5 \%)$ tidak menggunakan kelambu dan 15 responden $(37,5 \%)$ menggunakan kelambu.

Tabel 4. Distribusi Frekuensi Kejadian Penyakit Malaria di Wilayah Kerja Puskesmas Anggut Atas Kota Bengkulu

\begin{tabular}{|c|c|c|c|}
\hline $\begin{array}{l}\mathrm{N} \\
\mathrm{O}\end{array}$ & $\begin{array}{l}\text { Penyakit } \\
\text { Malaria }\end{array}$ & Frekuensi & $\begin{array}{c}\text { Persentase } \\
(\%)\end{array}$ \\
\hline 1 & Malaria (+) & 20 & 50,0 \\
\hline 2 & Malaria (-) & 10 & 50,0 \\
\hline & Jumlah & 40 & 100 \\
\hline
\end{tabular}

Dari Tabel 3 menunjukkan bahwa dari 40 responden terdapat 20 responden $(50,0 \%)$ malaria $(+)$ dan 20 responden $(50,0 \%)$ malaria $(-)$.

\section{Analisi Bivariat}

Tabel 5. Hubungan antara Pengetahuandengan Kejadian Penyakit malaria di Wilayah Kerja Puskesmas Anggut Atas Kota Bengkulu

\begin{tabular}{lccccccccc}
\hline \multirow{2}{*}{ Pengetahuan } & \multicolumn{2}{c}{ Malaria (+) } & \multicolumn{2}{c}{ Malaria (-) } & \multicolumn{2}{c}{ Total } & \multirow{2}{*}{$\mathrm{X}^{2}$} & \multirow{2}{*}{$\mathrm{P}$} & \multirow{2}{*}{ C } \\
& $\mathrm{F}$ & $\%$ & $\mathrm{~F}$ & $\%$ & $\mathrm{~F}$ & $\%$ & & \multirow{2}{*}{0,427} \\
\hline Kurang & 13 & 76,5 & 4 & 23,5 & 17 & 100 & \multirow{2}{*}{8,934} & 0,011 & 0,427 \\
Cukup & 4 & 40,0 & 6 & 60,0 & 10 & 100 & & \\
\hline
\end{tabular}




\begin{tabular}{|c|c|c|c|c|c|c|}
\hline \multirow{2}{*}{ Baik } & 3 & 21,1 & 10 & 76,9 & 13 & 100 \\
\hline & 20 & 50,0 & 20 & 50,0 & 40 & 100 \\
\hline
\end{tabular}

Dari Tabel 5 menunjukkan bahwa dari dari 17 responden pengetahuan kurang terdapat 13 responden malaria $(+)$ dan 4 responden malaria (-) dan dari 10 responden pengetahuan cukup terdapat 4 responden malaria $(+)$ dan 6 responden malaria (-) dan dari 13 responden pengetahuan baik terdapat 3 responden malaria (+) dan 10 responden malaria (-) di Wilayah Kerja Puskesmas Anggut Atas Kota Bengkulu.

Untuk mengetahui hubungan pengetahuan dengan kejadian penyakit malaria digunakan uji Pearson ChiSquare. Hasil uji Pearson Chi-Square didapat sebesar 8,934 dengan nilai asymp.sig $(\mathrm{p})=0,011$. Karena nilai $\mathrm{p}<0,05$ berarti Ho ditolak dan $\mathrm{Ha}$ diterima maka ada hubungan yang signifikan antara pengetahuan dengan kejadian penyakit malaria di Wilayah Kerja Puskesmas Anggut Atas Kota Bengkulu.

Keeratan hubungan tingkat pengetahuan dengan kejadian Penyakit malaria di Wilayah Kerja Puskesmas Anggut Atas Kota Bengkulu dilihat dari nilai Contingency Coefficient (C). Nilai C didapat sebesar 0,427. Karena nilai tersebut tidak terlalu jauh dari nilai $\mathrm{C}_{\max }$ $=0,707$ maka kategori hubungan tersebut dikatakan sedang.

Tabel 6. Hubungan Sikap dengan Kejadian Penyakit Malaria di Wilayah Kerja Puskesmas Anggut Atas Kota Bengkulu

\begin{tabular}{cccccccccc}
\hline \multirow{2}{*}{ Sikap } & \multicolumn{2}{c}{ Malaria (+) } & \multicolumn{2}{c}{ Malaria (-) } & \multicolumn{2}{c}{ Total } & \multirow{2}{*}{$\mathbf{x}^{2}$} & \multirow{2}{*}{$\mathrm{P}$} & \multirow{2}{*}{$\mathbf{C}$} \\
& $\mathbf{F}$ & $\%$ & $\mathbf{F}$ & $\%$ & $\mathbf{F}$ & $\%$ & & \\
\hline Unfavourable & 15 & 71,4 & 6 & 28,6 & 21 & 100 & & & \\
Favourable & 5 & 26,3 & 14 & 73,7 & 19 & 100 & 6,416 & 0,011 & 0,411 \\
Total & 20 & 50,0 & 20 & 50,0 & 40 & 100 & & & \\
\hline
\end{tabular}

Dari Tabel 6 menunjukkan bahwa dari 21 responden dengan sikap unfavourable terdapat 15 responden malaria $(+)$ dan 6 responden malaria (-) dan dari 19 responden dengan sikap favourable terdapat 5 orang malaria (+) dan 14 responden malaria (-) di Wilayah Kerja Puskesmas Anggut Atas Kota Bengkulu. Untuk mengetahui hubungan sikap dengan kejadian Penyakit malaria di Wilayah Kerja Puskesmas Anggut Atas Kota Bengkulu digunakan uji Chi-Square (Continuity Correction). Hasil uji ChiSquare (Continuity Correction) didapat sebesar 6,416 dengan nilai asymp.sig $(p)=0,011$. Karena nilai $p<0,05$ berarti Ho ditolak dan $\mathrm{Ha}$ diterima artinya ada hubungan yang signifikan antara sikap dengan kejadian Penyakit malaria di Wilayah Kerja Puskesmas Anggut Atas Kota Bengkulu.

Keeratan hubungan sikap dengan kejadian Penyakit malaria di Wilayah Kerja Puskesmas Anggut Atas Kota Bengkuludilihat dari nilai Contingency Coefficient (C). Nilai C didapat sebesar 0,411 . Karena nilai tersebut tidak terlalu jauh dari nilai $\mathrm{C}_{\max }=0,707$ maka kategori hubungan tersebut dikatakan sedang.

Tabel 7. Hubungan Pemakaian Kelambu dengan Kejadian Penyakit Malaria di Wilayah Kerja Puskesmas Anggut Atas Kota Bengkulu 


\begin{tabular}{cccccccccc}
\hline $\begin{array}{c}\text { Pemakaian } \\
\text { Kelambu }\end{array}$ & \multicolumn{2}{c}{ Malaria (+) } & \multicolumn{2}{c}{ Malaria } & \multicolumn{2}{c}{ Total } & $\mathbf{x}^{2}$ & P & C \\
\hline Tidak & F & $\%$ & F & $\%$ & F & $\%$ & & & \\
Menggunakan & 16 & 64,0 & 9 & 36,0 & 25 & 100 & & & \\
Menggunakan & 4 & 26,7 & 11 & 73,3 & 15 & 100 & 3,840 & 0,05 & \\
Total & 20 & 50,0 & 20 & 50,0 & 40 & 100 & & & \\
\hline
\end{tabular}

Dari Tabel 7 menunjukkan bahwa dari 25 responden tidak menggunakan kelambu terdapat 16 responden malaria (+) dan 9 responden malaria $(-)$ dan dari 15 responden menggunakan kelambu terdapat 4 responden malaria (+) dan 11 responden malaria (-) di Wilayah Kerja Puskesmas Anggut Atas Kota Bengkulu.

Untuk mengetahui hubungan pemakaian kelambu dengan kejadian Penyakit malaria di Wilayah Kerja Puskesmas Anggut Atas Kota Bengkulu digunakan uji Chi-Square (Continuity Correction). Hasil uji Chi-Square (Continuity Correction) didapat sebesar 3,840 dengan nilai asymp.sig $(\mathrm{p})=0,050$. Karena nilai $\mathrm{p}=0,05$ berarti Ho ditolak dan Ha diterima artinya ada hubungan yang signifikan antara sikap dengan kejadian Penyakit malaria di Wilayah Kerja Puskesmas Anggut Atas Kota Bengkulu.

Keeratan hubungan pemakaian kelambu dengan kejadian Penyakit malaria di Wilayah Kerja Puskesmas Anggut Atas Kota Bengkulu dilihat dari nilai Contingency Coefficient (C). Nilai C didapat sebesar 0,340 . Karena nilai tersebut jauh dari nilai $\mathrm{C}_{\max }=0,707$ maka kategori hubungan tersebut dikatakan lemah.

\section{PEMBAHASAN}

Berdasarkan hasil penelitian terdapat hubungan yang signifikan antara pengetahuan dengan kejadian penyakit malaria dengan kategori hubungan sedang. Pengetahuan tentang situasi malaria di suatu daerah akan sangat membantu program pemberantasan malaria dan berperan juga dalam melindungi masyarakat dari infeksi malaria agar paradigma sehat dapat diwujudkan.

Pengetahuan merupakan salah satu faktor yang mendorong terjadinya penyakit termasuk penyakit malaria. ${ }^{(10)}$ Pengetahuan merupakan domain yang sangat penting untuk terbentuknya prilaku seseorang, termasuk diantaranya prilaku dalam upaya-upaya pencegahan dan pengobatan malaria. Persepsi yang keliru tentang penyebab dan cara penularan malaria dapat mengarahkan pada prilaku masyarakat yang tidak benar terutama pada upaya-upaya pencegahan dan pengobatan penyakit malaria.

Penelitian ini sejalan dengan penelitian yang dilakukan oleh Sir dkk pada tahun 2014 yang menyatakan bahwa ada hubungan antara pengetahuan dengan kejadian malaria di Kecamatan Kabola Kabupaten Alor Provinsi Nusa Tenggra Timur (NTT). Sejalan dengan penelitian yang dilakukan oleh Rubianti dkk pada tahun 2009 yang menyatakan bahwa ada hubungan antara pengetahuan dengan kejadian malaria di Wilayah Kerja Pusksmas Paruga Kota Bima Nusa Tenggara Barat.

Penelitian ini sejalan dengan penelitian yang dilakukan oleh Nurdin dkk pada tahun 2013 yang menyatakan bahwa ada hubungan antara pengetahuan dengan kejadian malaria di wilayah Tambang Emas Kecamatan Nagari Kabupaten Sijunjung. 
Penelitian ini tidak sejalan dengan penelitian yang dilakukan oleh Retdianto pada tahun 2014 yang menyatakan bahwa tidak ada hubungan antara pengetahuan dengan kejadian penyakit malaria di Puskesmas Sungai Durian.

Penelitian ini juga tidak sejalan dengan penelitian yang dilakukan oleh Santi dkk pada tahun 2014 yang menyatakan bahwa tidak ada hubungan antara pengetahuan dengan kejadian malaria di Desa Sungai Ayak 3 Kecamatan Belitang Hilir Kabupaten Sekadau.

Hasil penelitian antara Sikap dengan Kejadian Penyakit Malaria terdapat hubungan yang signifikan antara sikap dengan kejadian penyakit malaria dengan kategori hubungan sedang. Hasil penelitian ini sejalan dengan teori yang disampaikan Notoadmodjo (2007), menyatakan bahwa sikap merupakan reaksi atau respon yang masih tertutup dari seseorang terhadap stimulus atau objek. Sikap yang positif akan cenderung membawa masyarakat untuk bertindak dalam mencegah terjadinya penularan penyakit termasuk penyakit malaria, Sikap secara nyata menunjukkan konotasi adanya kesesuaian reaksi terhadap stimulus yang dalam kehidupan sehari-hari yang merupakan reaksi yang bersifat emosional terhadap stimulus sosial. Sikap yang positif akan cenderung membawa masyarakat untuk mencegah terjadinya penularan penyakit termasuk penyakit malaria.

Sikap yang positif akan cenderung membawa masyarakat untuk bertindak dalam mencegah terjadinya penularan penyakit termasuk penyakit malaria.

Penelitian ini sejalan dengan penelitian yang dilakukan oleh Sir dkk pada tahun 2014 yang menyatakan bahwa ada hubungan antara sikap dengan kejadian malaria di Kecamatan Kabola Kabupaten Alor Provinsi Nusa Tenggra Timur (NTT).

Penelitian ini sejalan dengan penelitian yang dilakukan oleh Lumolo dkk (2015) yang menyatakan bahwa ada hubungan antara sikap dengan kejadian malaria di Wilayah Kerja Puskesmas Mayumba Provinsi Sulawesi Tengah. Penelitian ini tidak sejalan dengan penelitian yang dilakukan oleh Santi dkk pada tahun 2014 yang menyatakan bahwa tidak ada hubungan antara sikap dengan kejadian malaria di Desa Sungai Ayak 3 Kecamatan Belitang Hilir Kabupaten Sekadau.

Hasil penelitian antara pemakaian kelambu dengan kejadian penyakit malaria terdapat hubungan yang signifikan antara pemakaian kelambu dengan kejadian Penyakit malaria dengan kategori hubungan lemah. Hasil penelitian ini sejalan dengan teori Arsin (2012), bahwa usaha yang paling mungkin dilakukan adalah usaha pencegahan terhadap penularan parasit. Tindakan protektif ini bertujuan untuk mengurangi kontak manusia dengan nyamuk baik untuk orang per orang ataupun keluarga dalam satu rumah. Salah satu tindakan protektif ini yaitu dengan menggunakan kelambu tidur dengan atau tanpa intektisida pada saat tidur. Hasil penelitian ini tidak sejalan dengan penelitian yang dilakukan oleh Rubianti dkk pada tahun 2009 yang mengatakan bahwa tidak ada hubungan pemakaian kelambu dengan kejadian malaria di Puskesmas Paruga Kota Bima Nusa Tenggara Barat. Hasil yang sama juga dikemukakan oleh Retdianto dkk pada tahun 2014 yang menyatakan bahwa tidak ada hubungan pemakaian kelambu berinsektisida dengan kejadian malaria di Puskesmas Sungai Durian.

Penelitian ini sejalan dengan penelitian yang dilakukan oleh Santi dkk pada tahun 
2014 yang menyatakan bahwa ada hubungan antara pemakaian kelambu dengan kejadian malaria di Desa Sungai Ayak 3 Kecamatan Belitang Hilir Kabupaten Sekadau.

\section{KESIMPULAN}

1. Dari 40 responden, ada 17 responden (42,5\%) yang berpengetahuan kurang Di Wilayah Kerja Puskesmas Anggut Atas Kota Bengkulu

2. Dari 40 responden, terdapat 21 responden $(52,5 \%)$ dengan sikap unfavourable Di Wilayah Kerja Puskesmas Anggut Atas Kota Bengkulu.

3. Dari 40 responden, terdapat 25 responden $(62,5 \%)$ tidak menggunakan kelambu Di Wilayah Kerja Puskesmas Anggut Atas Kota Bengkulu.

4. Dari 40 responden, ada 20 orang (50,0\%) mengalami kejadian malaria (+) Di Wilayah Kerja Puskesmas Anggut Atas Kota Bengkulu.

5. Ada hubungan yang signifikan antara pengetahuan dengan kejadian penyakit malaria di Wilayah Kerja Puskesmas Anggut Atas Kota Bengkulu, dengan kategori hubungan sedang.

6. Ada hubungan yang signifikan antara sikap dengan kejadian penyakit malaria di Wilayah Kerja Puskesmas Anggut Atas Kota Bengkulu, dengan kategori hubungan sedang.

7. Ada hubungan yang signifikan antara pemakaian kelambu dengan kejadian penyakit malaria di Wilayah Kerja Puskesmas Anggut Atas Kota Bengkulu, dengan kategori hubungan lemah.

\section{DAFTAR PUSTAKA}

Sucipto CD. 2015. Manual Lengkap Malaria. Gosyen Publishing. Yogyakarta.

WHO. 2012. World Malaria Report. Geneve: World Health Organization.

Widoyono. 2011. Penyakit Tropis Epidemiologi, Penularan, Pencegahan dan Pemberantasannya. Jakarta. Erlangga.

Kunoll FJ. 2013. Pengantar Epidemiologi Penyakit Menular untuk Mahasiswa Kesehatan Masyarakat. Trans Info Media. Jakarta:

WHO. 2015. Fact Sheet: World Malaria Report. Geneve: World Health Organization.

Kemenkes R.I. 2016. Profil Kesehatan Indonesia.2015. Kementerian Kesehatan Republik Indonesia. Jakarta.

Dinkes Provinsi Bengkulu. 2016. Profil Kesehatan Provinsi Bengkulu. Dinas Kesehatan Provinsi Bengkulu. Bengkulu.

Dinas Kesehatan Kota Bengkulu. 2016.

Profil Kesehatan Kota Bengkulu Tahun 2015. Bengkulu: Dinas Kesehatan Kota Bengkulu.

Puskesmas Anggut Atas Bengkulu. Laporan Tahunan Puskesmas Anggut Atas Tahun 2015. Bengkulu: Puskesmas Anggut Atas Bengkulu,; 2016.

Arsin AA. 2012. Malaria di Indonesia Tinjauan Aspek Epidemiologi. Makassar: Masagena Press.

Gunawan S. 2000. Epidemiologi Malaria In: Harijanto PN, editor. Malaria Epidemiologi Patogenesis Manifestasi Klinis dan Penaganan. Jakarta: EGC. 
Notoatmodjo S. 2007. Promosi Kesehatan dan Ilmu Perilaku. Jakarta: Rineka Cipta.

Sastroasmoro S, Sofyan I. 2011. DasarDasar Metodologi Penelitian Klinis. Ke-4 ed. Jakarta: CV Sagung Seto.

Notoatmodjo S. 2010. Metodologi Penelitian Kesehatan. Jakarta: Rineka Cipta.

Haman H. 2001. Perilaku Manusia dan Lingkungan Sebagai Faktor Risiko Kejadian Malaria di Propinsi Jawa Tengah Berita Kedokteran Masyarakat;3 No XVII:157-69.

Sir O, Arsin A, Syam I, Despitasari M. 2014. Faktor-Faktor yang Berhubungan dengan Kejadian Malaria di Kecamatan Kabola Kabupaten Alor Provinsi Nusa Tenggara Timur (NTT) Tahun 2014. Ekologi Kesehatan 2014;14 No 4:334-41.

Rubianti I, Wibowo TA, Solikhah. 2009. Faktor-Faktor Risiko Malaria di Wilayah Kerja Puskesmas Paruga Kota Bima Nusa Tenggara Barat. Kesehatan Masyarakat;3 No 3:17484.

Nurdin E, Masrizal, Elytha F. 2013. Faktor Risiko Kejadian Penyakit Malaria di Wilayah Tambang Emas Kecamatan IV Nagari Kabupaten Sijunjung. Kesehatan Masyarakat;7 No 1:16-20. Retdianto V, Khayan. 2014. Hubungan Pengetahuan, Sikap dan Perilaku Pemakaian Kelambu Berinsektisida dengan Malaria di Puskesmas Sungai Durian. Sanitarian Jurnal Kesehatan;6 No 1:46-50.

Santy, Fitriangga A, Natalia D. 2014. Hubungan Faktor Individu dan Lingkungan dengan Kejadian Malaria di Desa Sungai Ayak 3
Kecamatan Belitang Hilir Kabupaten Sekadau. e-JKL; 2 no 1:265-72.

Lumolo F, Pinontoan OR, Rattu JM. 2015. Analisis Hubungan Antara Faktor Perilaku dengan Kejadian Malaria di Wilayah Kerja Puskesmas Mayumba Provinsi Sulawesi Tengah. eBiomedik(eBm); 3 No 3:865-71. 